\title{
Proceeding Paper \\ Investigating the Participation Facets of Environmental Citizen Science Initiatives: A Systematic Literature Review of Empirical Research ${ }^{+}$
}

\author{
Michalis A. Vasiliades ${ }^{1}$, Andreas Ch. Hadjichambis ${ }^{1,2, *(\mathbb{D})}$, Demetra Hadjichambi ${ }^{1,2}$, Anastasia Adamou ${ }^{1}$ D \\ and Yiannis Georgiou 1,2 \\ 1 Cyprus Centre for Environmental Research and Education (CYCERE), Limassol 3304, Cyprus; \\ mv.kykpee@gmail.com (M.A.V.); d.hadjichambi@cytanet.com.cy (D.H.); na.kykpee@gmail.com (A.A.); \\ yg.kykpee@gmail.com (Y.G.) \\ 2 Cyprus Ministry of Education, Culture, Sport and Youth (MOEC), Nicosia 1434, Cyprus \\ * Correspondence: a.hadjichambis@cytanet.com.cy; Tel.: +357-99477309 \\ + Presented at the 2nd International Conference of International Researchers of the Education for \\ Environmental Citizenship 2022, 10-11 March 2022. Available online: https:/ / enec-cost.eu/ireec22/.
}

check for

updates

Citation: Vasiliades, M.A.;

Hadjichambis, A.C.; Hadjichambi, D.;

Adamou, A.; Georgiou, Y.

Investigating the Participation Facets of Environmental Citizen Science

Initiatives: A Systematic Literature

Review of Empirical Research. Environ.

Sci. Proc. 2022, 14, 1. https://

10.3390/environsciproc2022014001

Academic Editors: Pedro Reis,

Marie-Christine Knippels, Audronè

Telesiene, Daphne Goldman, Jan

Cincera and Kateřina Jančaříková

Published: 25 February 2022

Publisher's Note: MDPI stays neutral with regard to jurisdictional claims in published maps and institutional affiliations.

Copyright: (C) 2022 by the authors. Licensee MDPI, Basel, Switzerland. This article is an open access article distributed under the terms and conditions of the Creative Commons Attribution (CC BY) license (https:// creativecommons.org/licenses/by/ $4.0 /)$
Abstract: Citizen science (CS) has shown tremendous popularity in recent years; however, there is still a lack of understanding of important aspects that determine citizens' participation and involvement in CS initiatives. Although CS initiatives could serve as a means of promoting forms of participation that contribute to the democratization of science, limited attention is still being paid to the "citizen" component of the citizen science term. For this reason, a systematic literature review (SLR), aligned with the PRISMA methodology, was applied to empirical studies on citizens' participation in environmental and nature-based CS initiatives established over the last two decades. The participatory aspect of the retrieved 119 CS initiatives was analysed on the basis of: (a) citizens' participation and (b) environmental citizenship. Our findings show that the majority of the CS initiatives were mostly limited to the local scale, and they primarily followed the contributory model, in which volunteers were mostly treated as "data collectors". Therefore, it is important to overcome barriers related to the design and implementation of CS that hinder citizens' participation and, at the same time, to strengthen democratization through a more participatory engagement of active and aware citizens, thus promoting environmental citizenship.

Keywords: participation aspects; environmental citizen science; facilitators; constraints; models and practices; education for environmental citizenship

\section{Introduction}

Citizen science (CS) has a long history, and it describes the involvement of members of the public in scientific research, mainly through forms of data collection and information gathering in various fields of science, such as nature, ecology, and the environment [1-5]. The interaction between the public and scientists can be considered as a two-way process that, on the one hand, promotes public participation in science, where among other things, the former acquire knowledge and skills during their involvement in data collection processes, and on the other hand, the latter use the large-scale data collected, which may not be easily gathered with other techniques, for the common good [6,7]. Despite the long history of CS, there are still several limitations in the underlying models and frameworks that guide public participation in CS initiatives. In many CS initiatives, the citizens are merely treated as "data collectors" or "passive" participants [8], instead of "active citizens" [9]. This finding is not surprising, given that CS research is not focused, for instance, on how CS can help the public to understand and appreciate the power of science for socio-political and socio-cultural action [4]. 
However, CS can be an excellent venue for the democratization of science, by achieving an "inclusive" and active engagement of citizens in the scientific process. This study presents a systematic literature review (SLR) of the available empirical research on citizens' participation in environmental and nature-based CS. More specifically, the participatory aspects of a total of 119 CS initiatives were analysed according to: (a) the CS models and practices defining citizens' participation, and (b) the participation forms for the achievement of education for environmental citizenship.

\section{Methodology}

The published literature was surveyed using four electronic databases (Scopus, Web of Science, Education Research Complete, ERIC), and the retrieval of the empirical studies followed three sequential stages: (a) Identification, (b) Screening, (c) Eligibility (Figure 1).

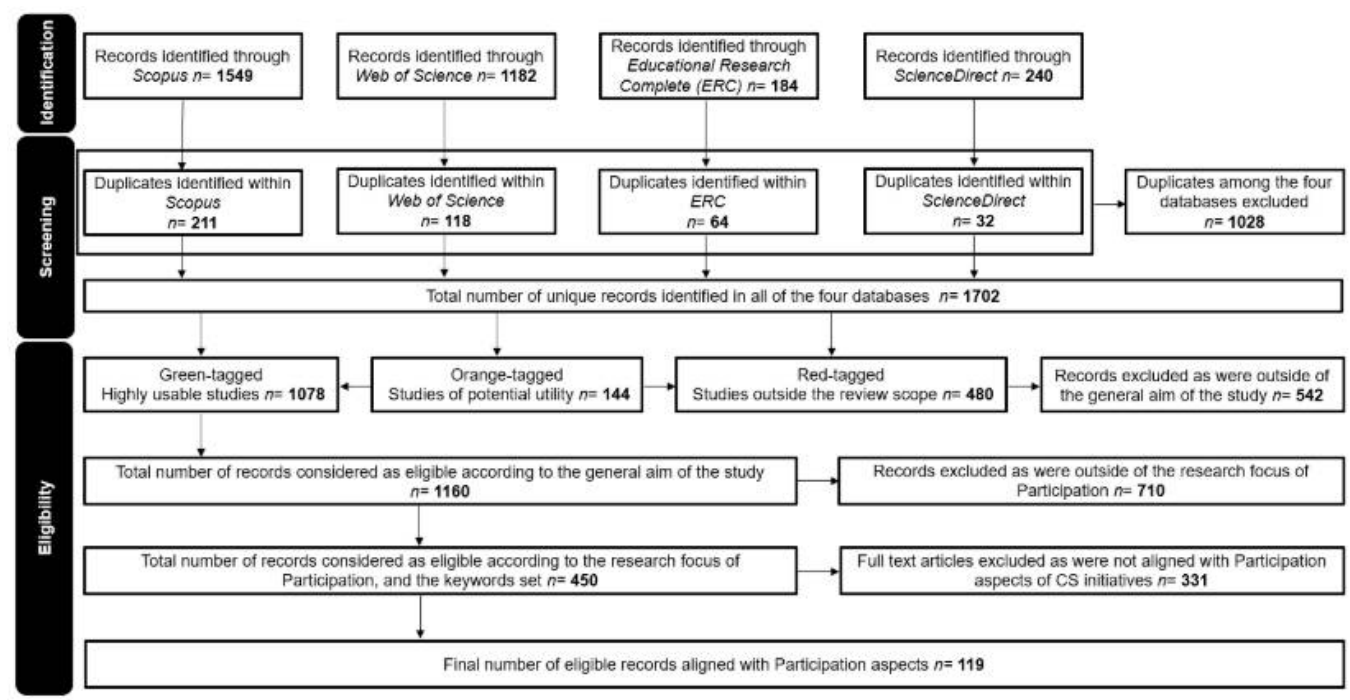

Figure 1. Flow diagram illustrating the review selection process.

This procedure resulted in 119 empirical studies, each one presenting a CS initiative; these were subjected to a content analysis, using a semi-structured checklist of CS participation-related typologies.

\section{Findings}

The majority of the reviewed CS initiatives were contributory and involved a single person as the data collector, mainly in the form of volunteering. Additionally, it was found that citizens were reporting multiple entries over an extended time period and were engaged only with data, contributing mainly to conducting and monitoring observations, along with collecting and submitting data, rather than being actively engaged with the whole process for a minimum duration (Figure 2).

Most of the studied CS initiatives targeted the "individual" and "private sphere" actions of EEC, which primarily took place on the "local" scale. The three main EEC outcomes reported in the reviewed CS initiatives were the development of a healthy relationship with nature, the solution of environmental problems, and the prevention of new environmental problems (Figure 3). 


\begin{tabular}{|c|c|c|c|}
\hline $\begin{array}{l}\text { (a) Level of data collection } \\
\text { - Single person }(58 \%)\end{array}$ & $\begin{array}{l}\text { (b) Forms of citizens' } \\
\text { participation }\end{array}$ & $\begin{array}{l}\text { (c) Frequency \& Duration } \\
\text { of participation }\end{array}$ & $\begin{array}{l}\text { (d) Types of citizens' contribution } \\
\text { - Contributory }(46 \%)\end{array}$ \\
\hline $\begin{array}{l}\text { - Small group of citizens (33\%) } \\
\text { Pair of citizens ( } 8 \%) \\
\text { - Entire community }(1 \%)\end{array}$ & $\begin{array}{l}\text { - Volunteering }(\mathbf{8 7 \%}) \\
\text { - Compensated }(\mathbf{1 1 \% )} \\
\text { - Pay to participate }(2 \%)\end{array}$ & $\begin{array}{l}\text { - Multiple times over an } \\
\text { extended period (74\%) } \\
\text { - One-time (26\%) }\end{array}$ & $\begin{array}{l}\text { - Contractual }(36 \%) \\
\text { - Collaborative }(18 \%)\end{array}$ \\
\hline
\end{tabular}

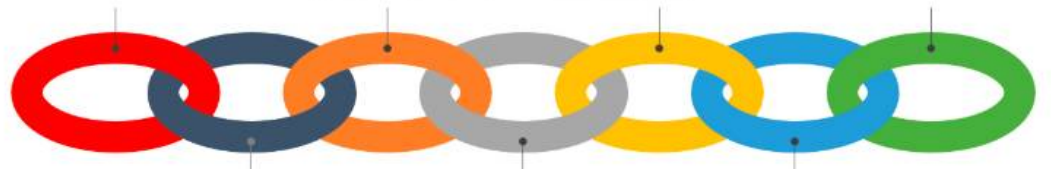

(e) Modes of engagement $\quad$ (f) Duration of engagement

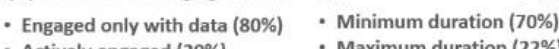

- Actively engaged $(20 \%)$ - Medium duration (8\%)
Maximum duration (22\%)

(g) Activities citizens involved

- Conducting and monitoring observations (37\%)

- Collecting and submitting data (35\%)

- Receiving training (14\%)

- Advising on analysis $(4 \%)$

- Designing study or protocol (3\%)

- Using data as evidence in decision making $(2 \%)$

- Drawing conclusions and desiminating results $(2 \%)$

- Defining the problem, issue or question (1\%)

- Asking new questions and taking actions $(1 \%$

- Developing research hypothesis (1\%)

Figure 2. (a) Level of data collection $(n=68)$, (b) Forms of citizens' participation $(n=74)$, (c) Frequency and duration ( $n=68)$ of citizens' participation, (d) Types of citizens' contributions $(n=65)$, $€$ Modes of engagement $(n=57)$, (f) Duration of engagement $(n=50)$, and (g) Citizens' activities $(n=63)$ in CS initiatives.

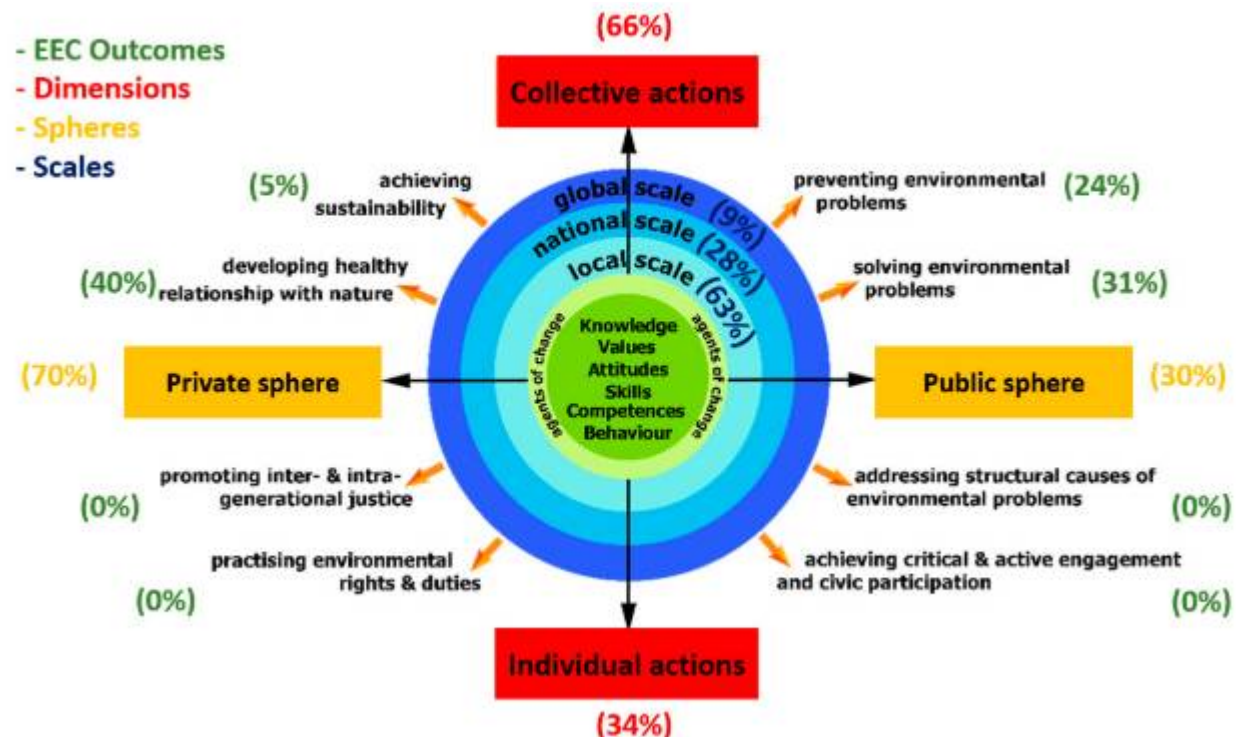

Figure 3. Dimensions, spheres, and scales as environmental citizenship actions $(n=33)$, as well as environmental citizenship outcomes $(n=17)$ promoted by the reviewed CS initiatives (Source Modified: [10]).

\section{Conclusions}

Our systematic literature review provides empirical substantiation on which environmental CS initiatives can support citizens' engagement with the underlying scientific processes, while also contributing to a broader, more inclusive, and active socio-political participation of citizens [11]. However, more efforts are needed to develop environmental citizenship with more focus on EEC actions situated in the collective dimension, public sphere, as well as on the national and global scale.

Author Contributions: Conceptualization, A.C.H. and D.H.; methodology, M.A.V., A.C.H., D.H., A.A. and Y.G.; software, M.A.V.; validation, A.C.H., D.H. and Y.G.; formal analysis, A.C.H.; investigation, M.A.V. and A.A.; resources, M.A.V., A.C.H., D.H., A.A. and Y.G.; data curation, M.A.V., A.A. and D.H.; writing—original draft preparation, M.A.V.; writing-review and editing, M.A.V., A.C.H., D.H. and Y.G.; visualization, A.C.H. and D.H.; supervision, A.C.H. and D.H.; project administration, 
M.A.V.; funding acquisition, A.C.H. and D.H. All authors have read and agreed to the published version of the manuscript.

Funding: This research was funded by EnviroCitizen Project. The EnviroCitizen project has received funding from the European Union's Horizon 2020 research and innovation programme under grant agreement No 872557.

Institutional Review Board Statement: Not applicable.

Informed Consent Statement: Not applicable.

Data Availability Statement: No new data were created or analysed in this study. Data sharing is not applicable to this article.

Acknowledgments: This study is partly inspired by the ENEC Cost Action-European Networks for Environmental Citizenship-CA16229 supported by COST (European Cooperation in Science and Technology-Horizon 2020).

Conflicts of Interest: The authors declare no conflict of interest.

\section{References}

1. Bonney, R.; Cooper, C.; Dickinson, J.; Kelling, S.; Phillips, T.; Rosenberg, K.V.; Shirk, J. Citizen Science: A Developing Tool for Expanding Science Knowledge and Scientific Literacy. BioScience 2009, 59, 977-984. [CrossRef]

2. $\quad$ Fritz, S.; See, L.; Carlson, T.; Haklay, M.M.; Oliver, J.L.; Fraisl, D.; Mondardini, R.; Brocklehurst, M.; Shanley, L.A.; Schade, S.; et al. Citizen Science and the United Nations Sustainable Development Goals. Nat. Sustain. 2019, 2, 922-930. [CrossRef]

3. Irwin, A. Citizen Science: A Study of People, Expertise, and Sustainable Development; Routledge: London, UK, $1995 ; \mathrm{p} .6$.

4. $\quad$ Oesterle, J.; Upadhyay, B.; Brown, J.C.; Vernon, M. Citizen Science: A Path to Democratic and Sociopolitically Conscious Science. In Handbook of Theory and Research in Cultural Studies and Education; Springer: Cham, Switzerland, 2020; pp. 1-30.

5. Wiggins, A.; Crowston, K. Goals and Tasks: Two Typologies of Citizen Science Projects. In Proceedings of the 201245 th Hawaii International Conference on System Sciences, Maui, HI, USA, 4-7 January 2012; pp. 3426-3435.

6. $\quad$ Dickinson, J.L.; Shirk, J.; Bonter, D.; Bonney, R.; Crain, R.L.; Martin, J.; Phillips, T.; Purcell, K. The Current State of Citizen Science as a Tool for Ecological Research and Public Engagement. Front. Ecol. Environ. 2012, 10, 291-297. [CrossRef]

7. Pretty, J.; Ball, A.; Benton, T.; Guivant, J.; Lee, D.R.; Orr, D.; Pfeffer, M.J.; Ward, H. The SAGE Handbook of Environment and Society; SAGE Publications Ltd.: London, UK, 2021.

8. Yadav, P.; Darlington, J. Conceptual Frameworks for Building Online Citizen Science Projects. Hum. Comput. 2016, 3, $213-223$. [CrossRef]

9. Jordan, R.C.; Gray, S.A.; Howe, D.V.; Brooks, W.R.; Ehrenfeld, J.G. Knowledge Gain and Behavioral Change in Citizen-Science Programs. Conserv. Biol. 2011, 25, 1148-1154. [CrossRef] [PubMed]

10. Hadjichambis, A.C.; Paraskeva-Hadjichambi, D. Education for Environmental Citizenship: The Pedagogical Approach. In Conceptualizing Environmental Citizenship for 21st Century Education; Hadjichambis, A.C., Reis, P., Paraskeva-Hadjichambi, D., Cincera, J., Boeve-de Pauw, J., Gericke, N., Knippels, M.-C., Eds.; Springer International Publishing: Cham, Switzerland, 2020; pp. 237-261, ISBN 978-3-030-20249-1.

11. Kenyon, E.; Christoff, A.; Wisdom, S. Citizen Science: Expanding Ideas of Citizenship and Science; Social Studies Research and Practice; Emerald Publishing Limited: Bingley, UK, 2020; Volume 15, pp. 83-96. 